\title{
Habitat selection of a coastal shark species estimated from an autonomous underwater vehicle
}

\author{
D. E. Haulsee ${ }^{1, *}$, M. W. Breece ${ }^{1}$, D. C. Miller ${ }^{1}$, B. M. Wetherbee ${ }^{2}$, D. A. Fox ${ }^{3}$, \\ M. J. Oliver ${ }^{1}$ \\ ${ }^{1}$ College of Earth, Ocean and the Environment, University of Delaware, Lewes, DE 19958, USA \\ ${ }^{2}$ Department of Biological Sciences, University of Rhode Island, Kingston, RI 02811, USA \\ ${ }^{3}$ Department of Agriculture and Natural Resources, Delaware State University, Dover, DE 19901, USA
}

\begin{abstract}
Quantifying habitat selection in marine organisms is challenging because it is difficult to obtain species location information with multiple corresponding habitat measurements. In the ocean, habitat conditions vary on many spatiotemporal scales, which have important consequences for habitat selection. While macroscale biotic and abiotic features influence seasonal movements (spatial scales of 100-1000 km), selectivity of conditions on mesoscales $(1-100 \mathrm{~km})$ reflects an animal's response to the local environment. In this study, we examined habitat selectivity by pairing acoustic telemetry with environmental habitat parameters measured by an autonomous underwater vehicle (AUV), and demonstrate that migrating sand tiger sharks Carcharias taurus along the East Coast of the USA did not randomly use the coastal environment. Of the variables examined, we found evidence to suggest that sand tigers were selecting their habitat based on distance to shore, salinity, and colored dissolved organic matter (CDOM). Notably, temperature was not predictive of habitat use in our study. We posit that during their coastal migration, sand tigers select for specific mesoscale coastal habitats that may inform navigation or feeding behaviors. To our knowledge, this is the first empirical measure of mesoscale habitat selection by a coastal marine organism using an AUV. The applications of this method extend beyond the habitat selectivity of sand tigers, and will prove useful for future studies combining in situ observations of marine habitats and animal observations.
\end{abstract}

KEY WORDS: Acoustic telemetry - Coastal habitats - Habitat utilization - Sand tiger shark · Autonomous underwater vehicle $\cdot$ Carcharias taurus

\section{INTRODUCTION}

The distribution of marine nekton is influenced by abiotic and biotic environmental cues on multiple spatial and temporal scales (Bowler \& Benton 2005, Nathan et al. 2008, Torres et al. 2008, Huijbers et al. 2012). Animals selecting for habitats in patchy environments may also have patchy distributions, reflecting variable oceanic conditions. Quantifying the underlying environmental mechanisms driving patchy distributions of marine organisms requires understanding where the organisms are, and the habitats available to them. A mobile species distribution is the

\footnotetext{
*Corresponding author: dhaulsee@udel.edu
}

integration of individual movements; each depending on the animal's physical ability to move and cognitive ability to navigate and respond to external factors (Nathan et al. 2008). The external cues that influence animal distributions depend on the perceptual range of the animal (Bowler \& Benton 2005) and its ability to interpret the detected environment (Nathan et al. 2008). Decisions regarding habitat selection are made on behavioral time scales, and are often based upon external cues sensed on scales relevant to the individual. In the aquatic realm, identifying external cues influencing mesoscale $(1-100 \mathrm{~km})$ habitat selectivity in the field is challenging and understudied.

() The authors 2015. Open Access under Creative Commons by Attribution Licence. Use, distribution and reproduction are unrestricted. Authors and original publication must be credited. 
Habitat selectivity has been defined as the disproportionate use of a habitat compared to its availability (Johnson 1980, Morrissey \& Gruber 1993, Manly et al. 2002, Aarts et al. 2008). Marine organisms can select and use preferable habitat on multiple scales (Levins 1968, Morris 1987, Bowler \& Benton 2005, Nathan et al. 2008). Morris (1987) explained the importance of understanding habitat selection at multiple scales in the environment, as these preferences can change at different spatiotemporal scales.

Researchers interested in habitat selection on macroscales (100-1000 km) have used satellite telemetry capable of estimating locations (accuracy of 1-10 km) of marine organisms for a few months to a year (Kobayashi et al. 2008, Weng et al. 2008, Block et al. 2011). These locations are then compared to habitat parameters, represented by remotely sensed sea surface conditions, or temperature and depth recorders within the tags themselves. The results of these studies are useful for understanding global scale conditions that restrict marine species distributions, but can be too large in geographic scale to identify the small-scale subsurface biotic and abiotic habitat conditions that drive local distributions.

Studies identifying mesoscale habitat use commonly use acoustic telemetry or visual sightings records to document species locations in the coastal ocean and estuaries (Heithaus et al. 2006, Torres et al. 2008, Huijbers et al. 2012, Kneebone et al. 2012). The coastal ocean presents additional challenges in habitat selection studies due to its physical dynamics. Currents, tides, freshwater inputs, nutrient loading and patchy prey distribution create an environment that varies on scales much smaller than those in the open ocean (Epifanio \& Garvine 2001). Within these mesoscale study regions, environmental conditions are measured using temperature loggers at fixed points (Kneebone et al. 2012), bathymetry maps and sediment type (Heithaus et al. 2006, Torres et al. 2008), or point source measurements of temperature, salinity, turbidity, and dissolved oxygen recorded near sightings of animals (Torres et al. 2008). In addition, auditory, olfactory and visual cues at smaller scales have been shown to affect juvenile reef fish habitat association in a laboratory setting (Huijbers et al. 2012), and studies have shown that salmonids use chemical cues in the water for natal stream homing behavior (Scholz et al. 1976, Dittman \& Quinn 1996).

The goal of this study was to demonstrate the utility of using an autonomous underwater vehicle (AUV) to identify mesoscale habitat selection for an imperiled species, the sand tiger shark Carcharias taurus. Sand tiger sharks (for brevity, hereafter sand tigers) are a top predatory shark found worldwide in coastal oceans, but are particularly concentrated in the MidAtlantic coastal ocean during the summer months (Castro 2011). Low fecundity and slow growth inhibits their populations from rebounding after disturbances from commercial fishing, spearfishing and protective beach meshing (Pollard \& Smith 2009). Thus, the National Oceanic and Atmospheric Administration (NOAA) have listed the sand tiger as a Species of Concern (Carlson et al. 2009) and globally they are listed as Vulnerable on the IUCN Red List (Pollard \& Smith 2009). Population assessments of the status of sand tigers in the western North Atlantic Ocean have varied widely, partly due to lack of ecological and biological information for this species (Musick et al. 1993, Carlson et al. 2009). Top predators including sand tigers may help maintain balance in marine ecosystems (Myers \& Worm 2005) since disruptions in top predator populations may change marine food webs (Myers et al. 2007). Declines in shark populations have been documented worldwide (Baum et al. 2003, Myers \& Worm 2003, Ferretti et al. 2010), and many studies cite lack of information regarding shark population size, behavior and habitat selection as key limitations in developing effective management strategies to assist population recovery. More information about mesoscale habitat selection by sand tigers during migration and the level of habitat selection in top predators in general would facilitate improved understanding of essential habitats, interactions with fisheries, and ultimately contribute to the conservation and recovery of this, and other imperiled species.

In this study, we examine local habitat selectivity of sand tigers during their coastal migration using a buoyancy controlled AUV. This AUV has integrated, near real-time, acoustic receivers and measures in situ water conditions associated with detections of acoustically telemetered sand tigers in the coastal Mid-Atlantic Ocean. This dataset allows us to not only quantify habitat selection, but to also make inferences about why certain habitat parameters may be important to a sand tiger. The null hypothesis in this study is that sand tigers are not selecting for specific habitats during their coastal migration.

\section{MATERIALS AND METHODS}

\section{Acoustic telemetry}

Sand tigers were captured and acoustically tagged between 2007 and 2012 as part of projects carried out 
by Delaware State University, University of Rhode Island, University of Massachusetts and the Massachusetts Division of Marine Fisheries (Kneebone et al. 2012); our study takes advantage of those ongoing tagging efforts. At the time of this study, there were 292 telemetered sand tigers in the western North Atlantic Ocean, from the projects mentioned above, serving as potential targets for detection by acoustic receivers. These sand tigers carried different models of transmitters (e.g. V16-6H, V16-4L, VEMCO) with varying nominal pulse rate depending on the intended study (see Table S1 in the Supplement at www.int-res.com/articles/suppl/m528p277_supp.pdf.) (tag details provided by: Atlantic Cooperative Telemetry [ACT] Network, Lori Brown pers comm, Kneebone et al. 2012). All sand tigers were internally tagged unless otherwise noted. The detectability of acoustic tags varies depending on the substrate and environmental conditions of the study area, as well as

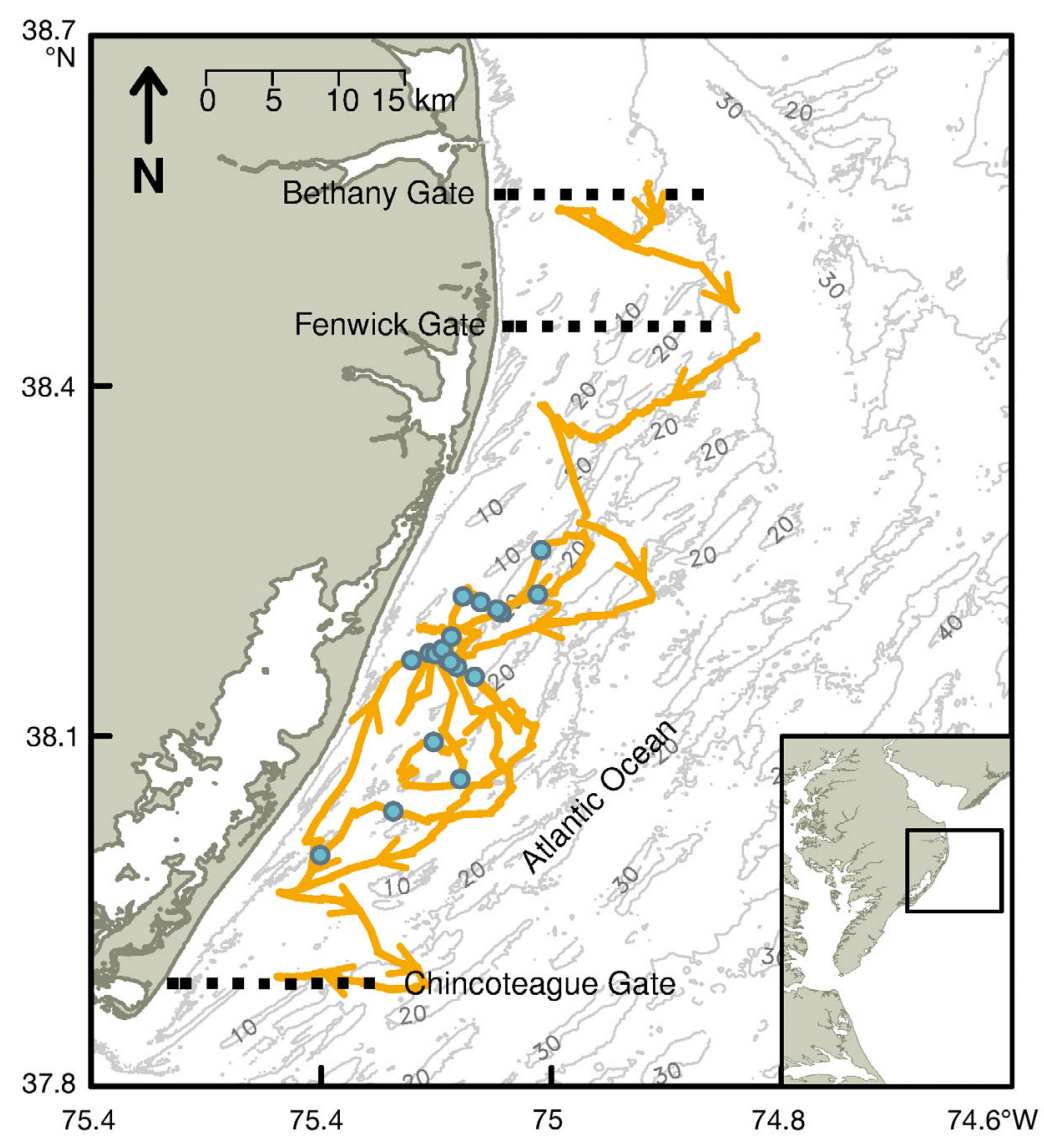

Fig. 1. Map of the autonomous underwater vehicle (AUV) track (gold line) along Delaware and Maryland coastlines from 5 to 23 October 2012. The AUV was deployed near the Bethany Gate, and generally traveled south (arrows indicate direction of travel), to the recovery location off of Chincoteague, Maryland. = locations of the acoustic receivers (VR2W) in the gate formations. $\mathrm{O}=$ median time of detection event for each sand tiger Carcharias taurus $(\mathrm{n}=23)$ detected by the AUV the size and power setting of each tag (How \& de Lestang 2012). Of the 292 sand tigers tagged, only 62 carried lower power (power output measured in $\mathrm{dB}$ re $1 \mu \mathrm{Pa} @ 1 \mathrm{~m})$ tags.

To capture the arrival and departure times of sand tigers within the coastal ocean, VEMCO VR-2W acoustic receivers were moored approximately $3 \mathrm{~m}$ off the sea floor, in gate formations perpendicular to the coastline at 3 locations (2 gates off Northern Delmarva Peninsula and 1 gate off Southern Delmarva Peninsula). These receivers can detect acoustic tags within approximately $800 \mathrm{~m}$, as demonstrated by preliminary range testing studies. The gates consisted of moored receivers placed at distances of $1,2,4,6,8,10,12,14$, and $16 \mathrm{~km}$ off Bethany Beach and Fenwick Island in Delaware, and Chincoteague Island in Maryland, USA (Fig. 1). Fenwick Gate is approximately $13 \mathrm{~km}$ south of Bethany Gate, while Chincoteague Gate is approximately $80 \mathrm{~km}$ south of Bethany Gate (Fig. 1).

Detections of telemetered sand tigers on these gates were used to estimate the timing and number of individuals migrating south along the coast during the fall of 2012. Detections were reduced to the number of individuals detected per receiver per day, or the number of detection events, so all individuals detected had equal weight. The percentage of detection events for each receiver within the gates was calculated by dividing the number of individual sand tiger detection events on a given receiver, by the total number of individual sand tiger detection events on all receivers during our study. For sand tigers that were detected by more than one of the gates, we calculated the mean time spent transiting gates, and the resulting approximate transiting speeds to estimate the detectability and direction of travel of sand tigers within our study.

\section{Autonomous underwater vehicle}

We integrated VR2C acoustic receivers (VEMCO; frequency $=69 \mathrm{kHz}$ ) into a buoyancy driven Slocum G2 Glider (Teledyne Webb Research). Acoustic receiver hydrophones extend out of both the dorsal and ventral hull to increase listening capabilities. The AUV travels in a 'saw-tooth' pattern, at approximately 
$0.2 \mathrm{~m} \mathrm{~s}^{-1}$ through the water column (Schofield et al. 2007), reporting its location and scientific data at predetermined surface intervals $(1-3 \mathrm{~h}$ depending on conditions). The low average speed of the AUV was half that of the average sand tiger transiting speed, and, thus unlikely to inhibit detection of migrating sand tigers.

In this study, the AUV was programmed to transit the coastal ocean in a general north-to-south direction while making east-west movements to sample waters that ranged between 8 and $25 \mathrm{~m}$ depth. The AUV was equipped with an EcoTriplet FLBBCD-SLK optical sensor (WetLabs), which measures the concentration of colored dissolved organic matter (CDOM), chl a and optical backscatter, a CTD (Seabird) from which salinity, temperature and depth were derived, and an Optode 3830 (Aandera) to measure dissolved oxygen. Environmental conditions are measured every few seconds, depending on the sensor.

Additional environmental parameters were calculated post-mission using data collected by the AUV. We calculated distance to land using the 'rdist.earth' function (Furrer et al. 2013) in the R statistical environment ( $\mathrm{R}$ Core Team 2013), to find the straight-line distance between every AUV position and the closest point to the medium resolution shoreline provided by the National Oceanic and Atmospheric Administration http://shoreline.noaa.gov/data/datasheets/ medres.html). Water depth at every AUV position was extracted from a high-resolution coastal relief map (ETOPO1) (Amante \& Eakins 2009). In addition, water density, sound speed, and integrated currents were calculated and tested for habitat selection, but these variables were not significant predictors of habitat selectivity and therefore not presented here.

Range testing of the acoustic receivers integrated into the AUV was completed in the spring of 2013, in the coastal ocean near Bethany Beach. To test the performance of the receivers, we flew the AUV near 4 moored VEMCO V16-6x coded acoustic tags (nominal delay $=880-920 \mathrm{~s}$ ). The distance from each test tag was calculated for every time step along the AUV track using the 'rdist.earth' function in R. Cumulative time (s) spent within distance bins $(0-250,251-500$, 501-750, 751-1000, 1001-2000 m) from each test tag was calculated. The expected number of transmissions per hour was calculated by multiplying the cumulative time the AUV spent in each distance bin, by the expected average number of test tag transmissions per hour. Dividing the measured number of detections from both receivers on the AUV within each distance bin, by the expected number of detec- tions within each bin, gave the proportion of test tag detected by the AUV at various distances away from the tags.

The AUV detected $97 \%$ of acoustic transmissions from test tags when it was within $250 \mathrm{~m}$ of a test tag. The percentage of tags detected decreased exponentially at distances greater than $250 \mathrm{~m}$ (see Fig. S1 in the Supplement). Some assumed spatial scale of environmental homogeneity is needed for any study that matches environmental data sets. For this study, we assume that a detected shark was within $250 \mathrm{~m}$ of the AUV, based on our range testing data. Since the AUV was never deeper than $30 \mathrm{~m}$, we are unable to determine the vertical position of any shark detected in the water column in relation to the AUV. To account for this, the environmental data were vertically collapsed and horizontally aggregated by computing the mean of the environmental data collected within $\pm 250 \mathrm{~m}$ of each meter along the AUV track. These averaged data represent the measured available habitat reference for sand tigers detected by the acoustic receivers within the AUV. Correlations among binned environmental variables were estimated using the Pearson product-moment correlation coefficient in R (R Core Team 2013), to supplement data interpretation.

Individual detections of sand tigers on the AUV ranged from 1 to 22 detections over the course of $1 \mathrm{~h}$. None of the sharks were re-detected after more than $11 \mathrm{~min}$. The median time of detection for each sand tiger detected was used to represent the detection event to evenly weight acoustic observations. Participants in the Atlantic Cooperative Telemetry (ACT) Network (www.theactnetwork.com) provided the metadata (e.g. sex, length, tagging location) for the sand tigers detected by the AUV. The receiver gate detection events were then visually compared to the detection events recorded by the AUV. Detections of sand tigers as a function of distance from shore were also compared between detection events on the acoustic gates and detection events on the AUV.

\section{Environmental selectivity analyses}

To test the null hypothesis that sand tigers do not exhibit habitat selectivity during their migration and are randomly distributed with respect to the habitat measured by the AUV, we used a 2-sample Kolmogorov-Smirnov (KS) test (Conover 1971). This test compares the distribution of an environmental parameter in a habitat to the distribution of that parameter where an individual was detected (Johnson 1980, 
Kobayashi et al. 2008). In this study, habitat utilization was the frequency distribution of each environmental variable in the $\pm 250 \mathrm{~m}$ where a sand tiger was detected by the AUV. Similarly, habitat availability was the frequency distribution of each environmental variable for the duration of the AUV mission.

Similar to Kobayashi et al. (2008), the cumulative distribution function (CDF) for habitat utilization and availability were compared using a 2-sample KS test in R (R Core Team 2013). The KS test compares the distributions and estimates the maximum vertical difference $\left(D_{\max }\right)$ between the 2 CDFs (Conover 1971). Directional 2-sided KS tests were performed to compare the central tendencies for habitat utilization and availability datasets (Hollander \& Wolfe 1973). The combination of these tests shows how the utilized habitat is different to the available habitat.

The vertical location of a detected shark in the water column was unknown, therefore we tested if surface or bottom (top $5 \mathrm{~m}$ and bottom $5 \mathrm{~m}$ ) conditions alone were associated with different habitat utilization. Water depth and distance to land were not included in this test because they do not change vertically in the water column. Similarly, we tested for differential habitat selection between males and females.

To reduce the potential for Type 1 error, we applied a randomization test with subsampling from the stratified AUV track, to ensure even sampling across the study domain. To do this, we partitioned the track into 4 quadrants (see Fig. S2 in the Supplement), which were equally sampled with replacement for 6 , 6,6 , and 5 points, mimicking the 23 detection events of sand tigers. We repeated this sampling 10000 times, and performed a 2-sided KS test for each of the bootstrapped samples comparing the distributions of the resampled environmental data points, with the remaining data points from the available habitat. A $D_{\max }$ statistic from the actual sand tiger detection samples within the $95 \%$ confidence interval of the randomly generated $D_{\max }$ values, would indicate that a Type I error was likely committed. This would indicate that we were wrongly rejecting the null hypothesis with respect to that specific environmental variable.

All interpretation of our results was based on the assumption that the available habitat was equally accessible to all sand tigers in our study. We think the available habitat was equally accessible because it is possible for a sand tiger to travel the spatial extent of the entire AUV mission within a short amount of time, allowing sand tigers to leave undesirable habitats. We also assume that the conditions measured by the AUV were representative of available sand tiger habitat. We think this is a valid assumption because the AUV sampled multiple transects over a long duration, capturing the available conditions during the study. Another assumption is that potential differences in detectability of transmitters did not bias our results. Thermally stratified systems can create socalled sound shadows in the water column and potentially influence transmitter detectability; however, these conditions were not observed by the AUV when sand tigers were encountered in our study. While these assumptions are not atypical for habitat selections studies (Aarts et al. 2008), we feel it is important to acknowledge them prior to interpreting specific habitat associations.

\section{RESULTS}

\section{Acoustic receiver gates}

Between 5 and 23 October 2012, 184 acoustically tagged sand tigers were detected on at least one of the moored acoustic gates off of the Delmarva Peninsula. Sharks detected by $>1$ gate spent (mean $\pm 1 \mathrm{SD}$ ) $9.15 \pm 6.22 \mathrm{~h},(\min .=4.33 \mathrm{~h}, \max .=26.12 \mathrm{~h}, \mathrm{n}=11)$ between Bethany and Fenwick Gates, $48.27 \pm$ $28.20 \mathrm{~h}$ (min. $=20.6 \mathrm{~h}, \max .=118.37 \mathrm{~h}, \mathrm{n}=12)$ between Fenwick and Chincoteague Gates, and $55.75 \pm 31.93 \mathrm{~h}(\min .=38.20 \mathrm{~h}, \max .=144.48 \mathrm{~h}, \mathrm{n}=$ 10) between Bethany and Chincoteague Gates. The mean transiting speed of all sand tigers detected by $>1$ gate during the study was $1.41 \pm 0.02 \mathrm{~km} \mathrm{~h}^{-1}(\mathrm{n}=$ 33), which is about twice the speed of the AUV. All sand tigers detected at more than one of the acoustic receiver gates were detected on a northern gate, followed by a southern gate; no individuals returned north after heading south. This indicates that all sand tigers detected on multiple gates were moving south, representative of a migration pattern.

\section{AUV mission}

The AUV was deployed approximately $12 \mathrm{~km}$ off of the Delaware coast near the Bethany Gate on 5 October 2012, and retrieved 19 d later (23 October 2012), approximately $7 \mathrm{~km}$ off of Chincoteague, Virginia (Fig. 1). During that $19 \mathrm{~d}$ interval, the AUV traveled $337 \mathrm{~km}$. The straight-line distance between deployment and recovery locations was $80 \mathrm{~km}$. The AUV was directed to sample across isobaths in a general southerly direction, but was occasionally direc- 
ted to return to areas of previous animal detections to see if the individuals remained in the area, or had moved on.

During the mission, the AUV detected 23 sand tigers (Table 1). The dorsal receiver recorded more individual detections ( $\mathrm{n}=$ $201)$, than the ventral receiver $(\mathrm{n}=59)$, but for the purposes of this study we combined data from both receivers and treat the AUV as a single receiver. All sand tigers detected by the AUV were detected by at least one of the moored receivers. The 23 detection events represent $12.5 \%$ of the sand tigers detected within the vicinity of the gates during the mission, while the individual moored receivers in the gates during this study detected on average $10.1 \%$ (range = $0.0-36.4 \%$ ) of the sand tigers. When compared to the individual moored receivers, the AUV ranked $10^{\text {th }}$ out of 26 in detection events within the study area.

Of the sand tigers detected by the AUV, 13 were male and 10 were female (Table 1). The mean $( \pm 1 \mathrm{SD})$ fork length of sand tigers detected was $177 \pm 30 \mathrm{~cm}$ at the time of capture (Table 1). Sharks 1 to 22 were originally tagged in the Delaware Bay, Delaware or the nearby coastal ocean between 2008 and 2012, while Shark 23 was tagged in the Plymouth Bay, Massachusetts in 2011 and was the only shark detected with a low power tag (Table 1).

Comparing the detection events on the receiver gates and on the AUV reveals that peak sand tiger activity at the gates coincided with the timing of the AUV mission in the coastal ocean (Fig. 2a). There was a peak in detection events at the 2 northern gates (Bethany and Fenwick) approximately $1 \mathrm{wk}$ before a peak in detection events at the southernmost gate (Chincoteague), more than $60 \mathrm{~km}$ away; the majority of AUV detections of individuals occurred between these 2 events (Fig. 2a). The number of sand tiger detection events on the AUV decreases similarly as the number of sand tiger detection events on all gates decreases (Fig. 2a). The bulk of the telemetered sand tigers transited the study area within an approximately 2 wk period, with individual sand tigers transiting the area in $2 \mathrm{~d}$, on average. Peak detection events on the gate receivers occurred on receivers located 1 and $2 \mathrm{~km}$ from shore, with the majority of detection events occurring less than $8 \mathrm{~km}$ from shore. Accounting for the fact that the AUV spent less time in areas 1 to $2 \mathrm{~km}$ from the shore (due to shallow
Table 1. Metadata for sand tigers Carcharias taurus detected by receivers on the autonomous underwater vehicle (AUV) between 5 and 3 October 2012. All sand tigers detected were tagged in Delaware with the exception of Shark 23, which was tagged in Plymouth Bay. All tags were high power tags, except Shark 23. Tags were interally planted, except for Sharks 1,12, 17 and 18, which were tagged externally. Dates given as mo/d/yr

\begin{tabular}{|c|c|c|c|c|c|c|}
\hline $\begin{array}{l}\text { Shark } \\
\text { ID }\end{array}$ & $\begin{array}{c}\text { Tagging } \\
\text { date }\end{array}$ & $\begin{array}{c}\text { AUV } \\
\text { detection } \\
\text { date }\end{array}$ & Sex & $\begin{array}{c}\text { Fork } \\
\text { length } \\
(\mathrm{cm})\end{array}$ & $\begin{array}{c}\text { No. of } \\
\text { detec- } \\
\text { tions }\end{array}$ & $\begin{array}{l}\text { Tag } \\
\text { type }\end{array}$ \\
\hline 1 & 8/15/12 & $10 / 10 / 12$ & Female & 181 & 7 & V16-5H \\
\hline 2 & $8 / 23 / 11$ & $10 / 10 / 12$ & Female & 217 & 6 & V16-6H \\
\hline 3 & $7 / 30 / 10$ & 10/11/12 & Female & 130 & 14 & V16-6H \\
\hline 4 & $8 / 4 / 10$ & $10 / 12 / 12$ & Female & 132 & 2 & V16-6H \\
\hline 5 & 8/17/09 & 10/12/12 & Female & 187 & 4 & V16-6H \\
\hline 6 & $8 / 17 / 12$ & 10/13/12 & Female & 170 & 2 & V16-6H \\
\hline 7 & $8 / 24 / 12$ & 10/13/12 & Female & 187 & 2 & VMT-1x \\
\hline 8 & $9 / 7 / 12$ & $10 / 15 / 12$ & Female & 210 & 11 & VMT-1x \\
\hline 9 & $8 / 3 / 10$ & 10/17/12 & Female & 130 & 11 & V16-6H \\
\hline 10 & $8 / 3 / 10$ & 10/18/12 & Female & 180 & 2 & V16-6H \\
\hline 11 & $8 / 23 / 10$ & $10 / 10 / 12$ & Male & 183 & 1 & V16-6H \\
\hline 12 & $8 / 11 / 12$ & $10 / 10 / 12$ & Male & 187 & 18 & V16-5H \\
\hline 13 & $8 / 24 / 12$ & $10 / 10 / 12$ & Male & 198 & 4 & VMT-1x \\
\hline 14 & $7 / 16 / 12$ & 10/11/12 & Male & 160 & 6 & V16-6H \\
\hline 15 & $7 / 27 / 11$ & $10 / 11 / 12$ & Male & 189 & 3 & V16-6H \\
\hline 16 & $7 / 22 / 10$ & 10/11/12 & Male & 178 & 3 & V16-6H \\
\hline 17 & 8/15/12 & $10 / 11 / 12$ & Male & 203 & 21 & V16-5H \\
\hline 18 & 8/10/12 & $10 / 12 / 12$ & Male & 210 & 1 & V16-5H \\
\hline 19 & $5 / 10 / 11$ & 10/13/12 & Male & 135 & 1 & V16-6H \\
\hline 20 & 8/30/12 & $10 / 13 / 12$ & Male & 200 & 22 & VMT-1x \\
\hline 21 & 10/1/08 & $10 / 14 / 12$ & Male & - & 21 & V16-6H \\
\hline 22 & $8 / 24 / 12$ & $10 / 16 / 12$ & Male & 202 & 3 & VMT-1x \\
\hline 23 & $7 / 15 / 11$ & 10/18/12 & Male & 117 & 1 & V16-4L \\
\hline
\end{tabular}

waters), detection events were similar to the peak AUV detection events at $6 \mathrm{~km}$ (Fig. 2b).

\section{Environmental conditions}

During the first $2 \mathrm{~d}$ of the AUV mission, the water column was vertically stratified; surface waters were warmer, more oxygenated, with lower salinity and higher chl a concentrations (Fig. 3). Vertical mixing occurred on 7 October 2012, resulting in a more homogenous water column (Fig. 3). After 9 October, water temperature cooled approximately $1^{\circ} \mathrm{C}$, while salinity increased by approximately 1 psu (Fig. 3a,b). Highest colored dissolved organic matter (CDOM) concentrations were generally near the bottom, indicating that decaying, organic-rich sediments was the major source of CDOM to the water column during this study (Fig. 3c, Coble et al. 2004). Chl a measurements reflected conditions typical of Mid-Atlantic coastal waters, ranging from 0.70 to $19.11 \mu g \mathrm{l}^{-1}$ 

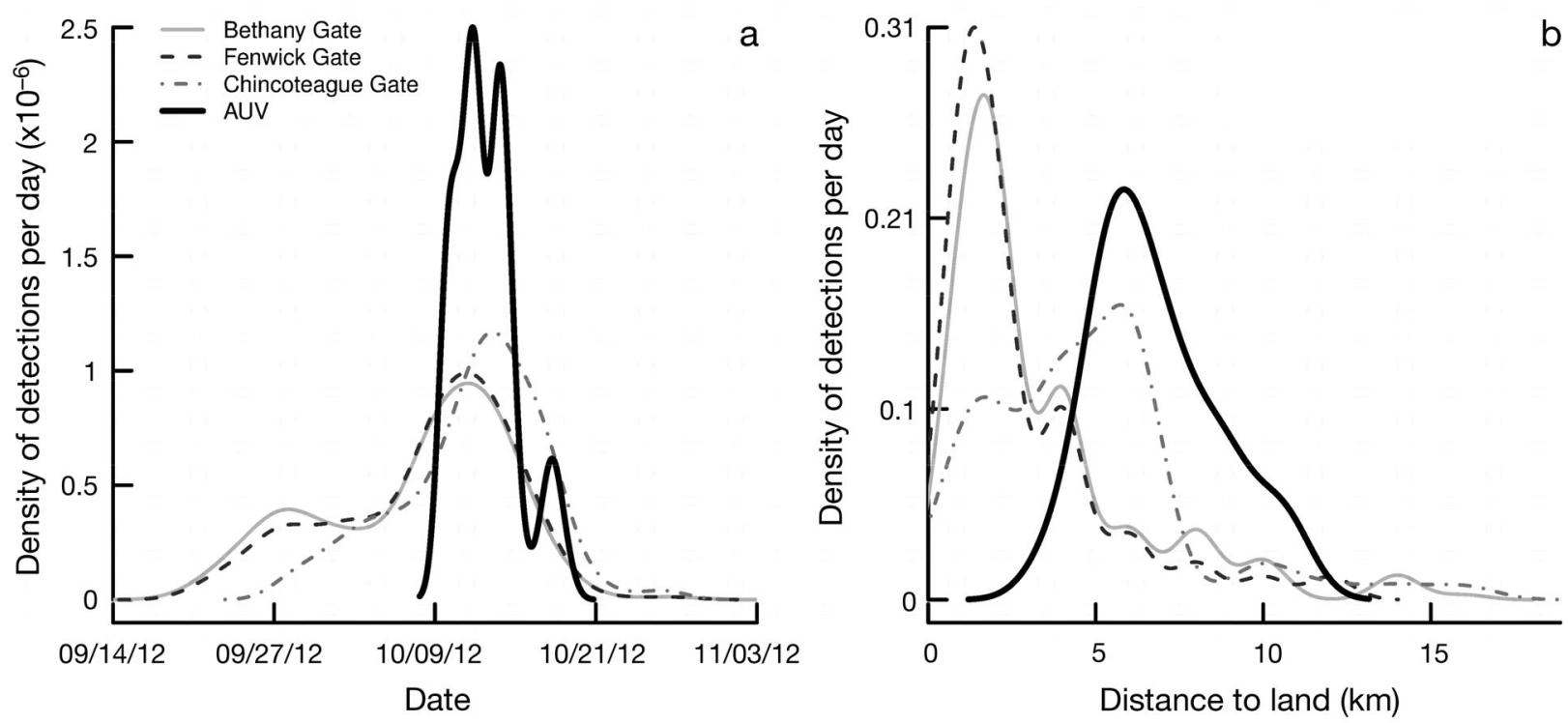

Fig. 2. Sand tiger Carcharias taurus detection events by acoustic receivers at the Bethany, Fenwick, and Chincoteague gates (22 August - 6 November 2012), and deployed on the autonomous underwater vehicle (AUV) (5-23 October 2012). (a) Density of sand tiger detection events over time and, (b) density of sand tiger detection events in relation to distance to land (km). Dates given as $\mathrm{mm} / \mathrm{dd} / \mathrm{yy}$

(Fig. 3d). Once the water column was mixed, the oxygen saturation in the water column varied little during the mission (Fig. 3e). The AUV sampled environmental conditions ranging from 2 to $20 \mathrm{~km}$ off the coast (Fig. 3f), over a range of water depths from 9 to $25 \mathrm{~m}$ (Fig. 1).

CDOM and distance to land were strongly negatively correlated $\left(\mathrm{r}_{\mathrm{S}}=-0.74, \mathrm{p}<0.001, \mathrm{df}=316,585\right)$, whereby CDOM increased as the distance to land decreased (see Fig. S3 in the Supplement). Chl a was strongly positively correlated with oxygen $\left(\mathrm{r}_{\mathrm{S}}=0.77\right.$, $\mathrm{p}<0.001, \mathrm{df}=316,585)$, and temperature was negatively correlated with salinity $\left(r_{S}=-0.66, p<0.001\right.$, df $=316586)$. Salinity was weakly negatively correlated with CDOM $\left(\mathrm{r}_{\mathrm{S}}=-0.40, \mathrm{p}<0.001\right.$, df $\left.=316585\right)$. Notably, water depth was only weakly positively correlated with distance to land $\left(\mathrm{r}_{\mathrm{S}}=0.47, \mathrm{p}<0.001, \mathrm{df}=\right.$ 316432) (Fig. S3).

\section{Habitat associations}

Salinity, CDOM and distance to land were significantly correlated with sand tiger detections (Fig. $4 \mathrm{a}-\mathrm{C}_{i}$ Table 2). Sand tigers selected waters that were lower in salinity, higher in CDOM and closer to shore compared to the available distribution of those variables on the AUV. The largest $D_{\max }$ comprised mean salinity of $31.8 \mathrm{psu}, \mathrm{CDOM}$ measured at $8.5 \mathrm{ppb}$ and was $8.7 \mathrm{~km}$ distance to land (Table 2).
Conversely, at the scale of our study, sand tigers were not selecting for water depth, temperature, chl a concentrations, or oxygen saturation (Fig. 4d, Table 2, see Fig. S4 in the Supplement). Our examination of the data generated through the randomization test with subsampling suggested that there was a low probability of committing a Type 1 error when rejecting our null hypothesis with respect to salinity, CDOM and distance to land (Table 2).

Using only the top $5 \mathrm{~m}$ and the bottom $5 \mathrm{~m}$ AUV data in our analyses provided similar results to using all of the AUV data (see Tables S2 \& S3 in the Supplement). In addition there was no significant difference in habitat selection between the males and females.

\section{DISCUSSION}

Many studies in the ocean have described the macroscale habitats of large marine predators (Kobayashi et al. 2008, Weng et al. 2008, Block et al. 2011). In contrast, our study focused on mesoscale habitat selection in dynamic neritic waters and demonstrates the utility of using AUVs equipped with environmental sensors to measure habitat associations of coastal marine species. In our study, sand tigers appeared to select for environmental variables that may be useful for navigation or feeding during their annual fall migration. 

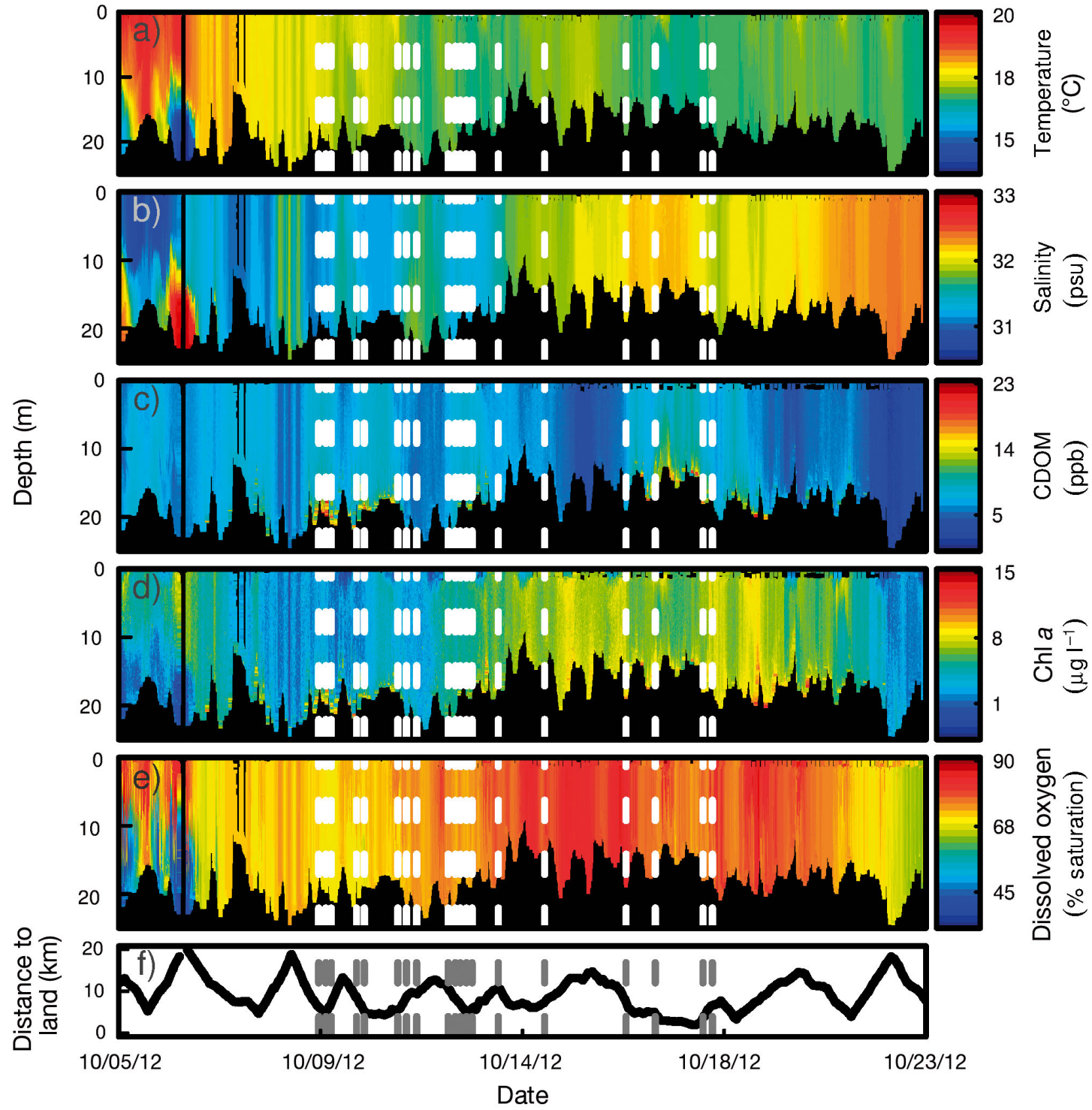

Fig. 3. Environmental conditions: (a) temperature $\left({ }^{\circ} \mathrm{C}\right)$, (b) salinity (psu), (c) colored dissolved organic matter, CDOM (ppb), $(\mathrm{d})$ chl a $\left(\mu \mathrm{g} \mathrm{l}^{-1}\right)$, and (e) dissolved oxygen (\% saturation), relative to water depth (m), measured by autonomous underwater vehicle (AUV) sensors during the mission. (f) Distance to land $(\mathrm{km})$. White and grey dashed vertical lines = median time point of detection for each of the 23 sand tigers, Carcharias taurus. In panels a-e, black $=$ areas where no data were collected. Dates given as mm/dd/yy

\section{Habitat selection}

Sand tigers detected by the AUV were close to shore and significantly associated with lower salinity and higher CDOM waters. In contrast, temperature, chl a concentration, oxygen saturation and water depth were not shown to be important habitat predictors on the scale of our investigation. Sand tigers are making large movements south along the East Coast during the fall to overwintering grounds off North Carolina and as far south as Florida (Kneebone et al. 2014); therefore, we interpret evidence of meso- scale habitat selection as possibly assisting in navigation or feeding activity during a time when the shark is transiting to their overwintering grounds.

Sand tigers were detected significantly closer to shore, but not in significantly shallower waters (Table 2). This may be a cue related to the proximity $(<10 \mathrm{~km})$ of crashing waves oriented parallel to the coastline. The sound from waves crashing on shore is likely within the detectable range of sharks (40$800 \mathrm{~Hz}$, Myrberg 2001), up to $9 \mathrm{~km}$ away from the shoreline (Wilson et al. 1985). Therefore, the sound of crashing waves could aid in navigation (Montgomery 
Table 2. Summary of the 2-sample Kolmogorov-Smirnov (KS) tests comparing the cumulative frequency distributions (CDF) of utilized and available habitat for detected sand tigers, Carcharias taurus. Included are the results of the randomization test with resampling, testing for spurious KS test results. $D_{\max }=$ largest vertical distance between points on the CDFs of utilized and available environmental variables. The value of the environmental variable associated with each $D_{\max }$ is presented. Randomization resampled significance values $<0.05$ indicate a Type 1 error was likely not committed. Bold indicates significance at $\mathrm{p}<0.05$. CDOM: colored dissolved organic matter

\begin{tabular}{|c|c|c|c|c|c|c|c|c|}
\hline \multirow{2}{*}{$\begin{array}{l}\text { Environmental } \\
\text { variable }\end{array}$} & \multicolumn{3}{|c|}{ Two-sided KS test } & \multicolumn{2}{|c|}{ CDF of $x$ lies above that of $y$} & \multicolumn{2}{|c|}{ CDF of $x$ lies below that of $y$} & \multirow{2}{*}{$\begin{array}{l}\text { Randomization } \\
\text { resampling test } \\
\text { significance }\end{array}$} \\
\hline & $\begin{array}{c}\text { Value at } \\
D_{\max }\end{array}$ & $D_{\max }$ & $\begin{array}{l}\text { Signifi- } \\
\text { cance }\end{array}$ & $D_{\max }$ & $\begin{array}{l}\text { Signifi- } \\
\text { cance }\end{array}$ & $D_{\max }$ & $\begin{array}{l}\text { Signifi- } \\
\text { cance }\end{array}$ & \\
\hline Temperature $\left({ }^{\circ} \mathrm{C}\right)$ & 18.91 & 0.21 & 0.379 & 0.21 & 0.191 & 0.10 & 0.702 & 0.389 \\
\hline Chl a $\left(\mu \mathrm{g} \mathrm{l}^{-1}\right)$ & 3.00 & 0.11 & 0.979 & 0.11 & 0.639 & 0.09 & 0.720 & 0.054 \\
\hline Salinity (psu) & 31.81 & 0.31 & 0.050 & 0.31 & 0.025 & 0.07 & 0.843 & 0.017 \\
\hline Oxygen (\% saturation) & 83.77 & 0.17 & 0.632 & 0.11 & 0.609 & 0.17 & 0.328 & 0.255 \\
\hline CDOM (ppb) & 8.53 & 0.32 & 0.038 & 0.04 & 0.931 & 0.32 & 0.019 & 0.018 \\
\hline Distance to land (km) & 8.74 & 0.40 & 0.005 & 0.40 & 0.002 & 0.06 & 0.865 & 0.002 \\
\hline Water depth (m) & 14.86 & 0.31 & 0.051 & 0.05 & 0.918 & 0.31 & 0.025 & 0.242 \\
\hline
\end{tabular}
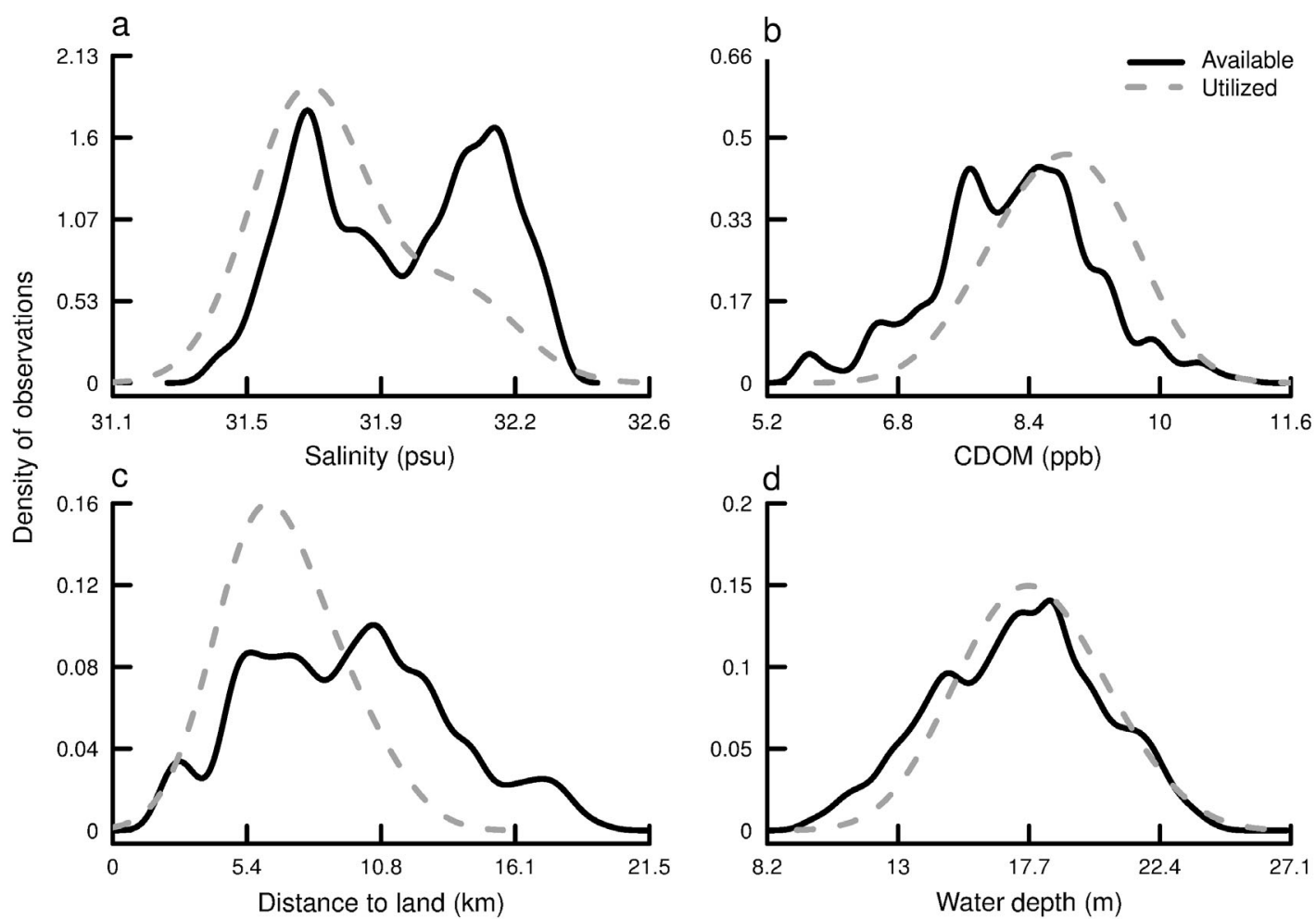

Fig. 4. Utilized and available density distributions of environmental variables (a) salinity (psu) and (b) colored dissolved organic matter, CDOM (ppb), measured by sensors in the autonomous underwater vehicle (AUV); (c) distance to land (km) and (d) water depth $(\mathrm{m})$, calculated from high-resolution coastline and bathymetry maps. Solid black line = available habitat, dashed gray line = habitat utilized by sand tigers, Carcharias taurus. Utilized habitats are the environmental variables matched to each sand tiger detection event, while available habitats are all data measured by AUV

\& Walker 2001), and be a possible explanation for the selection of near-shore waters. In addition, the presence of the physical coastline and shoals in the nearshore waters may serve as landmarks in a cognitive map used by sand tigers while migrating. This nearshore selectivity of sand tigers was observed both on the receiver gates and the AUV despite the shallow depth limitations of the AUV (Fig. 2b).
Lower salinity waters were also significantly related to the shark habitat utilization. Data measured by the AUV reveals that salinity was changing over space and time, and there was not one specific geographic area that had persistently low salinity. However, the change in salinity over the time frame of our study does not exceed the range sand tigers experience during a typical summer season within the 
Delaware Bay (e.g. 22.8-30.3 ppt, Merson \& Pratt 2001); therefore any potential selectivity of lower salinity habitats is not likely due to physiological constraints. Low salinity near the coast is often associated with the Delaware Bay freshwater plume, known to exit the bay and flow south along the coast (Sanders \& Garvine 1996, Geiger et al. 2013). While river plumes are ephemeral due to their connection with weather and wind events, sand tigers exiting the bay may use this freshwater plume as an additional navigational aid. This association with the lower salinity waters of the Delaware Bay plume has also been observed with Atlantic Sturgeon Acipenser oxyrinchus oxyrinchus during their fall migration along the Delmarva Peninsula (Oliver et al. 2013).

CDOM in the ocean is a complex mix of organic matter (e.g. proteins, amino acids) from decaying plant and animal material and grazing activity (Coble et al. 2004). In some systems, CDOM is associated with freshwater plumes (Opsahl \& Benner 1997, Oliver et al. 2004), however, in our study CDOM was weakly correlated with salinity and was strongly correlated with distance to land. During this study, the highest concentrations of CDOM were at the bottom, indicating that decaying organic-rich sediments was the source of CDOM (Fig. 3). This makes it difficult to interpret the relative importance of distance to land and CDOM concentrations for sand tiger habitat, since near-shore processes can mix CDOM from sediments into the water column. Possibly, sand tigers, whilst transiting an area, are choosing to do so in areas of high organic matter decomposition. The olfactory system in sharks is highly developed (Tester 1963), and sand tigers have one of the largest olfactory bulb to brain mass ratio of elasmobranchs (Jacobs 2012), suggesting that they have the cognitive ability to use odorants as navigational or feeding cues to map mesoscale habitats (Yopak et al. 2014).

The non-selectivity of temperature, chl $a_{\text {, oxygen }}$ saturation and water depth is equally noteworthy. On larger scales, the biogeography of sand tigers suggests that these variables may be important (Castro 2011). However, within the scope of our study and our relatively small sample size, we did not find evidence that these parameters played a role in mediating sand tiger distribution and habitat use. Also noteworthy was the weak correlation between water depth and distance to land; the numerous shoals that exist in our study domain most likely confound the relationship between these 2 variables. Water depth approaches significance at the $\alpha=0.05$ level ( $p=$ 0.051 ) in our selectivity analysis, however, our boot- strapping analysis suggests that it is only by chance that this was a nearly significant relationship (Table 2). It is possible that by broadening the spatiotemporal scope of our AUV mission, we would discover habitat selectivity for temperature, chl $a$, oxygen saturation and water depth; however, this would shift the focus of the study from mesoscale to macroscale habitat use.

\section{AUVs as effective telemetry assets}

Autonomous underwater vehicles equipped with telemetry devices are a maturing technology, and their ability to perform multiple sampling tasks with high spatial and temporal frequency complement existing telemetry sampling strategies (Grothues et al. 2008). This study is among the first to show that an AUV, integrated with acoustic receiver technology, can be used to detect in situ marine organism habitat selection (see Grothues et al. 2008, Clark et al. 2013, Oliver et al. 2013). The AUV mission occurred during the peak migration of sand tigers in the Delmarva coastal ocean. Throughout the $19 \mathrm{~d}$ AUV mission, $12.5 \%$ of the sand tigers swimming between the Bethany Gate and the Chincoteague Gate were detected by the AUV, which is closely comparable to the average detection efficiency of a single receiver in the moored acoustic arrays. While a well-designed receiver array can detect up to $100 \%$ of the animals in the system (Clements et al. 2005), it is not surprising that detecting a moving target with a mobile receiver would experience decreased detection efficiencies. Our results indicate that even though the AUV is moving, and the conditions change throughout the mission, the AUV integrated receivers performed at least as well as an individual receiver within the gates. This suggests that AUVs are effective and complementary telemetry assets (Eiler et al. 2013). In addition, the complementary information about in situ environmental conditions and the capability of detecting telemetered animals outside of the bounds of a moored acoustic array provide significant value to existing telemetry arrays.

\section{CONCLUSIONS}

This study captured a snapshot of the environmental conditions and habitat selectivity during the southward near-shore migration of sand tigers off the Mid-Atlantic coast in the fall. We have demonstrated a novel method for studying mesoscale habitat selec- 
tivity of a large, highly mobile species in a complex coastal ocean. Habitat parameters sensed by predators on small scales are often difficult to measure, and studies tend to focus on macroscale habitat selection. Our study serves as a stepping-stone towards understanding mesoscale habitat selection by a top predator during their seasonal migration in a complex coastal system. Sand tiger detection events on the receiver gates allowed us to determine that individual sharks were migrating south during our study, which is supported by the findings of Kneebone et al. (2014). We also observed evidence of habitat selection based on distance to shore, salinity and CDOM. Therefore, we considered those variables relevant to the migration pattern we observed. Our results suggest that sand tigers sense and respond to prominent dynamic features in the coastal ocean including salinity and CDOM, and that their movements may be highly correlated with such oceanographic features. Variance in sand tiger movement around the mean southward migration may be explained by changes in salinity or CDOM, and may provide a way to improve our biogeographic understanding of sand tigers in the coastal ocean. However, we acknowledge that there may be many factors affecting their distribution that we did not measure in this study.

By detecting oceanographic conditions that are associated with organism locations, inferences can be made about the habitat selectivity of the organisms. This is important information for managers because little is known about sand tiger behavior or what habitats they are using as they migrate along the East Coast of the USA. Globally, the sand tiger population is declining, and information regarding habitat selectivity in this study region may be applicable in other regions around the world. Expanding upon the methods presented here, we can begin to not only identify essential habitats for vulnerable species like sand tigers, but also the environmental characteristics of those habitats. We can then use this information to foster the conservation and recovery of sand tigers. Identifying predictive habitat parameters will assist managers in identifying potential human interactions with sand tigers that may be affecting their population (i.e. commercial and recreational fishing areas that are concentrated along the coast, increasing the probability of sand tiger bycatch). We think the pairing of acoustic telemetry and in situ measurements of the environment allows researchers and managers to gain an improved understanding of what habitats are important for species of interest, and will be critical in the future research of habitat selection and behavior of imperiled marine animals.
Acknowledgements. This work was generously supported by the Robertson's Fund, the Delaware Space Grant Consortium, the MARACOOS and the IOOS Program Office, the DuPont Clear into the Future Program Award to Delaware State University (DSU), Center for Integrated Biological and Environmental Research at DSU, Delaware EPSCor with funds from the National Science Foundation Grant (EPS0814251), and the NOAA-NMFS Proactive Conservation Program Award (NA09NMF4720365). The authors thank the RUCOOL team, C. Haldeman, D. Aragon, T. Haskins, and J. Kerfoot at Rutgers University for their vital assistance with AUV operations, piloting and data processing. We thank L. Brown and J. Kneebone, members of the ACT Network, for providing metadata associated with the animals detected in the study. M. Cimino and A. Davies provided insight that greatly improved our analysis of the dataset.

\section{LITERATURE CITED}

Aarts G, MacKenzie M, McConnell B, Fedak M, Matthiopoulos J (2008) Estimating space-use and habitat preference from wildlife telemetry data. Ecography 31:140-160

Amante C, Eakins BW (2009) ETOPO1 1 Arc-Minute Global Relief Model: procedures, data sources and analysis. NOAA Tech Memo NESDIS NGDC-24. National Geophysical Data Center, NOAA

Baum JK, Myers RA, Kehler DG, Worm B, Harley SJ, Doherty PA (2003) Collapse and conservation of shark populations in the Northwest Atlantic. Science 299:389-392

Block BA, Jonsen ID, Jorgensen SJ, Winship AJ and others (2011) Tracking apex marine predator movements in a dynamic ocean. Nature 475:86-90

Bowler DE, Benton TG (2005) Causes and consequences of animal dispersal strategies: relating individual behaviour to spatial dynamics. Biol Rev Camb Philos Soc 80: 205-225

Carlson JK, McCandless CK, Cortes E, Grubbs RD, Andrews KI, MacNeil MA, Musick JA (2009) Update on the status of the sand tiger shark, Carcharias taurus in the Northwest Atlantic Ocean. NOAA Technical Memorandum NMFS-SEFSC-585. National Marine Fisheries Service, Panama City, FL

Castro JI (2011) The sharks of North America. Oxford University Press, New York, NY

Clark CM, Forney C, Manii E, Shinzaki D and others (2013) Tracking and following a tagged leopard shark with an autonomous underwater vehicle. J Field Robot 30: 309-322

Clements S, Jepsen D, Karnowski M, Schreck CB (2005) Optimization of an acoustic telemetry array for detecting transmitter-implanted fish. N Am J Fish Manag 25: 429-436

Coble P, Hu C, Gould RW Jr, Chang G, Wood AM (2004) Colored dissolved organic matter in the coastal ocean: an optical tool for coastal zone environmental assessment and management. Oceanography 17:50-59

Conover WJ (1971) Practical nonparametric statistics. Wiley, New York, NY

Dittman A, Quinn T (1996) Homing in pacific salmon: mechanisms and ecological basis. J Exp Biol 199:83-91

Eiler JH, Grothues TM, Dobarro JA, Masuda MM (2013) Comparing autonomous underwater vehicle (AUV) and vessel-based tracking performance for locating acoustically tagged fish. Mar Fish Rev 75:27-42 
Epifanio C, Garvine R (2001) Larval transport on the Atlantic continental shelf of North America: a review. Estuar Coast Shelf Sci 52:51-77

Ferretti F, Worm B, Britten GL, Heithaus MR, Lotze HK (2010) Patterns and ecosystem consequences of shark declines in the ocean. Ecol Lett 13:1055-1071

Furrer R, Nychka D, Sain S (2013) fields: tools for spatial data. R package version 6.7.6, http://CRAN.R-project. org/package=fields

> Geiger EF, Grossi MD, Trembanis AC, Kohut JT, Oliver MJ (2013) Satellite-derived coastal ocean and estuarine salinity in the Mid-Atlantic. Cont Shelf Res 63:S235-S242

> Grothues TM, Dobarro J, Ladd J, Higgs A, Niezgoda G, Miller D (2008) Use of a multi-sensored AUV to telemeter tagged Atlantic sturgeon and map their spawning habitat in the Hudson River, USA. Autonomous Underwater Vehicles, 2008. AUV 2008. Woods Hole, MA, 13-14 October 2008. IEEE/OES, doi:10.1109/AUV.2008.5347597

Heithaus MR, Hamilton IM, Wirsing AJ, Dill LM (2006) Validation of a randomization procedure to assess animal habitat preferences: microhabitat use of tiger sharks in a seagrass ecosystem. J Anim Ecol 75:666-676

Hollander M, Wolfe DA (1973) Nonparametric statistical procedures. Wiley, New York, NY

> How JR, de Lestang S (2012) Acoustic tracking: issues affecting design, analysis and interpretation of data from movement studies. Mar Freshw Res 63:312-324

> Huijbers CM, Nagelkerken I, Lössbroek PAC, Schulten IE, Siegenthaler A, Holderied MW, Simpson SD (2012) A test of the senses: fish select novel habitats by responding to multiple cues. Ecology 93:46-55

Jacobs LF (2012) From chemotaxis to the cognitive map: the function of olfaction. Proc Natl Acad Sci USA 109: 10693-10700

> Johnson DH (1980) The comparison of usage and availability measurements for evaluating resource preference. Ecology 61:65-71

Kneebone J, Chisholm J, Skomal GB (2012) Seasonal residency, habitat use, and site fidelity of juvenile sand tiger sharks Carcharias taurus in a Massachusetts estuary. Mar Ecol Prog Ser 471:165-181

Kneebone J, Chisholm J, Skomal GB (2014) Movement patterns of juvenile sand tigers (Carcharias taurus) along the east coast of the USA. Mar Biol 161:1149-1163

Kobayashi DR, Polovina JJ, Parker DM, Kamezaki N and others (2008) Pelagic habitat characterization of loggerhead sea turtles, Caretta caretta, in the north pacific ocean (1997-2006): Insights from satellite tag tracking and remotely sensed data. J Exp Mar Biol Ecol 356:96-114

Levins R (1968) Evolution in changing environments: some theoretical explorations. Princeton University Press, Princeton, NJ

Manly BFJ, McDonald LL, Thomas DL, McDonald TL, Erickson WP (2002) Resource selection by animals: statistical analysis and design for field studies. Springer Netherlands, Dordrecht

Merson RR, Pratt HL Jr (2001) Distribution, movements and growth of young sandbar sharks, Carcharhinus plumbeus, in the nursery grounds of Delaware Bay. Environ Biol Fish 61:13-24

> Montgomery JC, Walker MM (2001) Orientation and navigation in elasmobranchs: Which way forward? Environ Biol Fish 60:109-116

Morris DW (1987) Ecological scale and habitat use. Ecology 68:362-369
Morrissey JF, Gruber SH (1993) Habitat selection by juvenile lemon sharks, Negaprion brevirostris. Environ Biol Fish 38:311-319

Musick JA, Branstetter S, Colvocoresses JA (1993) Trends in shark abundance from 1974 to 1991 for the Chesapeake Bight region of the U.S. Mid-Atlantic coast. In: Branstetter S (ed) Conservation biology of elasmobranchs. NOAA Tech Rep NMFS 115, p 1-18

> Myers RA, Worm B (2003) Rapid worldwide depletion of predatory fish communities. Nature 423:280-283

Myers RA, Worm B (2005) Extinction, survival or recovery of large predatory fishes. Philos Trans R Soc Lond B Biol Sci 360:13-20

Myers RA, Baum JK, Shepherd TD, Powers SP, Peterson CH (2007) Cascading effects of the loss of apex predatory sharks from a coastal ocean. Science 315:1846-1850

> Myrberg AA Jr (2001) The acoustical biology of elasmobranchs. Environ Biol Fish 60:31-46

Nathan R, Getz WM, Revilla E, Holyoak M, Kadmon R, Saltz D, Smouse PE (2008) A movement ecology paradigm for unifying organismal movement research. Proc Natl Acad Sci USA 105:19052-19059

> Oliver MJ, Glenn S, Kohut JT, Irwin AJ, Schofield OM, Moline MA, Bissett WP (2004) Bioinformatic approaches for objective detection of water masses on continental shelves. J Geophys Res 109, C7, doi:10.1029/2003JC 002072

> Oliver MJ, Breece MW, Fox DA, Haulsee DE, Kohut JT, Manderson J, Savoy T (2013) Shrinking the haystack: using an AUV in an integrated ocean observatory to map atlantic sturgeon in the coastal ocean. Fisheries 38: 210-216

> Opsahl S, Benner R (1997) Distribution and cycling of terrigenous dissolved organic matter in the ocean. Nature 386:480-482

Pollard D, Smith A (2009) Carcharias taurus. The IUCN Red List of Threatened Species Version 2014.3, www.iucn redlist.org (downloaded on 12 Nov 2014)

R Core Team (2013) R: a language and environment for statistical computing. R Foundation for Statistical Computing, Vienna

Sanders TM, Garvine RW (1996) Frontal observations of the Delaware coastal current source region. Cont Shelf Res 16:1009-1021

Schofield O, Kohut J, Aragon D, Creed L and others (2007) Slocum gliders: robust and ready. J Field Robot 24: 473-485

Scholz AT, Horrall RM, Cooper JC, Hasler AD (1976) Imprinting to chemical cues: the basis for home stream selection in salmon. Science 192:1247-1249

Tester AL (1963) The role of olfaction in shark predation. Pac Sci 17:145-170

Torres LG, Read AJ, Halpin P (2008) Fine-scale habitat modeling of a top marine predator: Do prey data improve predictive capacity? Ecol Appl 18:1702-1717

> Weng KC, Foley DG, Ganong JE, Perle C, Shillinger GL, Block BA (2008) Migration of an upper trophic level predator, the salmon shark Lamna ditropis, between distant ecoregions. Mar Ecol Prog Ser 372:253-264

> Wilson OB Jr, Wolf SN, Ingenito F (1985) Measurements of acoustic ambient noise in shallow water due to breaking surf. J Acoust Soc Am 78:190-195

> Yopak KE, Lisney TJ, Collin SP (2015) Not all sharks are 'swimming noses': variation in olfactory bulb size in cartilaginous fishes. Brain Struct Funct 220:1127-1143 